\title{
Validation of the Korean Bedtime Procrastination Scale in Young Adults
}

\author{
Hyeyoung An ${ }^{1}$, Sun ju Chung ${ }^{2}$, Sooyeon Suh ${ }^{1}$ \\ ${ }^{1}$ Department of Psychology, Sungshin Women's University, Seoul, \\ ${ }^{2}$ Department of Psychiatry, SMG-SNU Boramae Medical Center, Seoul, Korea
}

\author{
젊은 성인을 대상으로 한 한국판 취침시간 지연행동 척도 타당화 \\ 안혜영 ${ }^{1}$, 정선주 ${ }^{2}$, 서수연 ${ }^{1}$ \\ 성신여자대학교 심리학과, ${ }^{1}$ 보라매병원 정신건강의학과 ${ }^{2}$
}

\section{Received May 7, 2019 \\ Revised June 7, 2019 \\ Accepted June 19, 2019}

Address for correspondence

Sooyeon Suh, PhD

Department of Psychology,

Sungshin Women's University,

2 Bomun-ro 34da-gil,

Seongbuk-gu,

Seoul 02844 , Korea

Tel: $+82-2-920-7215$

Fax: +82-2-920-2040

E-mail: alysuh@sungshin.ac.kr
Objectives: Bedtime procrastination is defined as going to bed later than intended, without having external reasons for doing so. Despite various studies investigating the new concept of bedtime procrastination, there have been no studies that have validated the Bedtime Procrastination Scale (BPS). Thus, this study aims to validate the BPS in Korean. Methods: Two hundred twenty seven participants (mean age $22 \pm 2.39$ years, $81.1 \%$ female) participated in the study. All participants completed the BPS, Insomnia Severity Index, Center for Epidemiologic Studies Depression Scale, Perceived Stress Scale, Depressive Symptom InventorySuicidality Subscale, and General Procrastination Scale (GPS). Exploratory factor analysis was used to determine number of factors. Results: Exploratory factor analysis revealed support for one factor, which was consistent with the original study. Goodness of fit was adequate for the one factor model $\left[\chi^{2}=59.369(\mathrm{df}=27\right.$, $p<0.001$ ), Comparative Fit Index $=0.963$, Tucker-Lewis Index $=0.951$, Root Mean Square Error of Approximation $=0.073$, Standardized Root Mean Square Residual=0.042]. Internal consistency was also adequate (Cronbach's alpha $=0.86)$. Convergent validity was also high with the GPS $(p<0.001, \mathrm{r}=0.411)$. Correlations were also high with other questionnaires $(p<0.05)$. Conclusions: The BPS is a reliable and valid measure for bedtime procrastination, and may have important clinical implications for sleep disorders.

J Sleep Med 2019;16(1):41-47

Key Words: Sleep, Procrastination, Sleep deprivation, Factor analysis.

\section{서 론}

수면 부족은 운동, 인지, 정서를 포함한 인간의 기능을 크 게 저해하며, 건강 및 사회, 경제적으로 상당한 영향을 미치 는 심각한 문제로 알려져 있다. ${ }^{1,2}$ 네덜란드의 성인 인구 표 본 중 $50 \%$ 가 넘는 사람들이 한 주에 2일 이상 불충분한 수 면을 경험한다고 보고하며, 2016년 아동청소년인권실태조 사에 따르면, 우리나라 청소년 표본 9천여 명 중 54.1\%가 수 면이 부족하다고 보고하였다. 3,4 일반적으로 부족한 수면은 비만 및 에너지 대사에 중요한 역할을 하며, 청소년들의 경

This is an Open Access article distributed under the terms of the Creative Commons Attribution Non-Commercial License (https://creativecommons.org/licenses/by-nc/4.0) which permits unrestricted non-commercial use, distribution, and reproduction in any medium, provided the original work is properly cited.
우 졸리움이나 피로, 정서적인 변화, 주의와 수행에서의 변 화 등에 영향을 미칠 뿐만 아니라 주관적 행복감의 저하와 우울감 및 절망감, 자살사고를 증가시키고 건강 위해 행동 (예를 들어, 흡연 및 음주)을 증가시킨다..$^{5-7}$ 이러한 수면 부 족은 다양한 원인으로 인해 발생할 수 있는데, 청소년들의 경우 최근에 중요한 개념으로 '취침시간 지연행동(bedtime procrastination)'이 제안되었다.

취침시간 지연행동이란 “외부적인 요인이 없음에도 불구 하고 자발적으로 원래 의도한 것보다 늦게 잠자리에 드는 행동”을 의미한다. ${ }^{8}$ 이는 일반적 지연행동에서 확장된 개념 으로서 일반 대중들의 수면 부족은 수면장애나 외부적인 요 인(예를 들어, 교대근무)으로 인해 발생하는 것이 아니라 잠 자리에 들 의도와 실제 행동이 일치하지 않는 건강 행동 문 
제에 따른 것으로 간주할 수 있다는 관점을 포함한다. ${ }^{3}$ 따라 서 취침시간 지연행동의 중요한 전제 조건 중 하나는 일반 지연행동의 정의와 마찬가지로 "부정적인 결과가 예측됨에 도 불구하고” 수행한다는 것이다. ${ }^{8-10}$

이런 맥락에서 취침시간 지연행동의 부정적인 영향에 대 한 연구 결과들이 존재한다. Kroese 등의 연구에 따르면 취 침시간 지연행동은 불충분한 수면 및 수면시간과 관련되며, 취침시간 지연행동을 많이 할수록 피로와 주간 졸리움의 수 준이 높다고 알려졌다. ${ }^{8}$ 또한 취침시간 지연행동은 자기 자 비, 부정적인 정서와도 관련되어, 취침시간 지연행동을 많이 할수록 자기 자비의 수준이 낮고 부정적인 정서의 수준이 높다. ${ }^{11}$ 국내에서의 연구에 따르면 취침시간 지연행동을 많 이 하는 사람일수록 우울과 일반적인 불안 성향, 일시적으로 느끼는 불안 상태의 수준이 높고, 기상 시각 또한 지연될 뿐 만 아니라 수면 효율성과 주관적인 수면의 질이 낮다는 것 이 밝혀졌다(정선주, 미출간 데이터). 이 외에도 취침시간 지 연행동으로 인한 부정적인 영향은 아니지만, 일반적으로 취 침시간 지연행동의 정도가 높은 사람들은 높은 일반 지연행 동, 자기 조절 능력 부족, 저녁형 일주기 유형과 관련이 있는 것으로 알려져 있다. ${ }^{8,12}$

취침시간 지연행동 양상에 대한 연구 결과들도 존재한다. Exelmans와 Van den Bulck의 연구에 따르면 자기 통제와 취침시간 지연행동 사이에 전자 미디어인 TV 시청의 사용 이 영향을 미친다. ${ }^{13}$ 즉, 낮은 자기 통제력이 저녁시간의 TV 시청과 TV에 대한 자기 조절 능력 부족에 영향을 미치고, 이는 취침시간 지연행동으로 이어진다. 또한 젊은 성인 98 명 을 대상으로 한 24시간 생활시간 조사 결과에 따르면, 미디 어를 이용한 여가활동에 많은 시간을 소비하는 사람일수록 취침시간 지연행동을 더 많이 하는 것으로 나타났으며, 그 하위 영역으로는 컴퓨터와 휴대전화를 사용한 여가활동이 취침시간 지연행동과 유의했다(정선주, 미출간 데이터). 이 외에도 스마트폰 중독이 수면시간과 수면 부족을 유의하게 예측한다는 연구가 존재하는데, 앞의 결과들을 토대로 스마 트폰 중독과 수면시간 및 수면 부족 사이에 취침시간 지연 행동이 관련될 수 있다는 예측을 해볼 수 있다. ${ }^{14}$

최근 취침시간 지연행동에 대한 연구가 활발히 진행되면 서 취침시간 지연행동의 기제와 영향, 이에 대한 개입 방법 에 대한 관심으로 연구의 흐름이 이어지고 있다. 이와 함께 취침시간 지연행동의 정도를 측정할 수 있는 '취침시간 지연 행동 척도(Bedtime Procrastination Scale, BPS)'에 대한 타 당화 연구의 필요성이 제시되고 있다. 이에 따라 본 연구는 지연행동을 많이 하는 것으로 알려진 초기 성인기를 대상으 로, 국내외의 타당화가 부재한 BPS의 타당화를 위한 연구를
실시하며, 이를 통해 BPS의 타당도와 신뢰도를 검증하고 내 적 구조를 확인하고자 하였다. ${ }^{15} \mathrm{BPS}$ 의 수렴 타당도는 취침 시간 지연행동과 관련이 높다고 알려진 일반 지연행동을 이 용하여 확인할 것이다. ${ }^{8}$ 이에 더불어 취침시간 지연행동이 부정적 정서와 관련 있다는 선행연구를 바탕으로, 국내에서 의 연구가 현저하게 부족한 취침시간 지연행동의 심리적 특 성을 알아보기 위해 취침시간 지연행동과 불면증 심각도, 우 울, 지각된 스트레스, 자살사고 사이의 관련성을 보고자 하 였다. ${ }^{11}$ 본 연구를 통해 BPS는 향후 취침시간 지연행동 연구 에 있어 중요한 지표로 활용될 것이다. 종합하면 본 연구에 서는 취침시간 지연행동의 정도를 측정하는 한국판 $\mathrm{BPS}$ 의 타당도와 신뢰도 검증 및 내적 구조를 확인하며, 취침시간 지연행동과 심리적 변인 사이의 관계를 확인하고자 하였다. 이에 따른 연구 문제는 다음과 같다.

연구 문제 1. 한국판 BPS의 내적 일치도 및 신뢰도를 검증 한다.

연구 문제 2. 한국판 BPS의 수렴 타당도를 검증하고, 내적 구조를 확인한다.

연구 문제 3. 취침시간 지연행동과 불면증 심각도, 우울, 지각된 스트레스, 자살사고 사이의 관련성을 확인한다.

\section{방 법}

\section{연구 대상 및 절차}

본 연구는 2016년부터 2017년까지 모집한 20 30대 성인 227 명을 대상으로 수행되었다. 참가자들은 자발적으로 연구 참여에 동의한 심리학 수업을 수강하는 학부생들과 일반인 으로, 사전 동의를 구한 이후 설문지를 실시하였다. 전체 표 본 227명을 대상으로 BPS의 내적 일관성 신뢰도, General Procrastination Scale(GPS)과의 수렴 타당도 및 내적 구조 를 평가하고, 취침시간 지연행동과 심리적 변인들 간의 관계 를 확인하기 위해 분석을 실시하였다. 본 연구는 성신여자대 학교 기관생명윤리위원회(Institutional Review Board, IRB) 의 승인을 받았다(IRB 승인번호: SSWUIRB 2016-063, SSWUIRB 2017-016, SSWUIRB 2017-006).

\section{측정 도구}

\section{취침시간 지연행동 척도(Bedtime Procrastination Scale)}

본 연구는 취침시간 지연행동을 측정하기 위해 Kroese 등 이 개발하고 국내 연구자 2명이 번안한 취침시간 지연행동 척도(BPS)를 사용하였다(정선주, 미출간 데이터). ${ }^{8}$ 계획했던 
것보다 잠자리에 늦게 들어가는 행동의 정도를 측정하는 총 9 개의 문항으로 구성되어 있다. 2, 3, 7, 9번은 역채점하며, 각 문항은 1 5점으로 평가된다. 총점은 9 45점으로 총점이 높을수록 취침시간 지연행동의 정도가 심한 것을 의미한다. Kroese 등의 연구에서 내적 일치도 계수(Cronbach's $\alpha$ )는 0.92 이며, 본 연구에서의 내적 일치도 계수(Cronbach's $\alpha$ )는 0.86 이다. $^{8}$

\section{일반적 지연행동 척도(General Procrastination Scale)}

본 연구는 전체 표본 227명 중 173명을 대상으로, 일반적 지연행동을 측정하기 위해 Lay가 개발하고 Lim이 번안한 일 반적 지연행동 척도 $(\mathrm{GPS})$ 를 사용하였다. ${ }^{916}$ 본 척도는 다양 한 일상 상황에서 안정적으로 나타나는 지연행동의 정도를 측정하며, BPS의 수렴 타당도를 검증하기 위해 사용되었다. 총 20 개의 문항으로 구성되어 있으며, $3,4,6,8,11,13,14$, $15,18,20$ 번 문항은 역채점한다. 각 문항은 1 5점으로 평가 하고, 총점이 높을수록 일반적 지연행동의 정도가 심한 것을 의미한다. Lay의 연구에서 내적 일치도 계수(Cronbach's $\alpha$ ) 는 0.82 이며, 본 연구에서의 내적 일치도 계수(Cronbach's $\alpha$ ) 는 0.90 이다. ${ }^{9}$

\section{불면증 심각도 척도(Insomnia Severity Index)}

본 연구는 불면증 심각도를 파악하고자 Bastien 등이 개발 하고 Cho 등이 타당화한 한국판 불면증 심각도 척도(Insomnia Severity Index, ISI)를 사용하였다. ${ }^{17,18}$ 총 7문항으로 구성되어 있으며, 각 문항은 최근 2주간 경험한 불면증의 심 각도와 현재 수면에 대한 만족도, 주간 기능 손상, 수면에 대 한 걱정, 삶의 질 손상을 0 4점으로 평가한다. 총점은 0 28 점이며, 한국판 불면증 심각도 척도의 경우 총점이 15점 이 상이면 불면증 위험군으로 분류한다. Cho 등의 연구에서 내 적 일치도 계수(Cronbach's $\alpha$ )는 0.92이며, 본 연구에서의 내적 일치도 계수(Cronbach's $\alpha$ )는 0.79 이다. ${ }^{18}$

\section{우울 척도(Center for Epidemiologic Studies \\ Depression Scale)}

본 연구는 Radloff가 개발하고 Chon 등이 통합적 한국판 으로 타당화한 우울 척도(Center for Epidemiologic Studies Depression Scale, CES-D)를 사용하였다. ${ }^{19,20}$ 지난 1 주간 경 험한 우울 증상의 빈도를 0 3점으로 측정하는 총 20개의 문 항으로 구성되어 있으며, $4,8,12,16$ 번 문항은 역채점한다. 총점은 0 60점으로 16점 이상의 경우 우울증 위험군으로 분 류할 수 있다. Chon 등의 연구에서 내적 일치도 계수(Cronbach's $\alpha$ )는 0.91이며, 본 연구에서의 내적 일치도 계수(Cron- bach's $\alpha$ )는 0.92 이다. ${ }^{20}$

\section{지각된 스트레스 척도(Perceived Stress Scale)}

본 연구는 지각된 스트레스의 정도를 파악하기 위해 $\mathrm{Co}^{-}$ hen 등이 개발하고 Park과 Seo가 타당화한 지각된 스트레 스 척도(Perceived Stress Scale, PSS)를 사용하였다. ${ }^{21,22}$ PSS 는 지난 한 달간 개인이 경험한 일상 상황에 대해 스트레스 로 지각하는 정도를 0 4점으로 평가하는 총 10 개의 문항으 로 구성되어 있다. 4, 5, 6, 7, 8번 문항은 역채점하며, 총점은 0 40점으로 점수가 높을수록 지각된 스트레스 수준이 높다 는 것을 의미한다. Park과 $\mathrm{Seo}$ 의 연구에서 내적 일치도 계수 (Cronbach's $\alpha$ )는 0.77 이며, 본 연구에서의 내적 일치도 계수 (Cronbach's $\alpha$ )는 0.71이다.22

\section{자살사고 척도(Depressive Symptom Inventory- Suicidality Subscale)}

본 연구는 자살사고 수준을 평가하기 위해 Metalsky와 Joiner Jr가 개발하고 Suh 등이 타당화한 무망감 우울증상 척도(Hopelessness Depression Symptom Questionnaire)의 자살 경향에 대한 하위 척도(Depressive Symptom Inventory-Suicidality Subscale, DSI-SS)를 사용하였다. ${ }^{23,24}$ 본 척도 는 최근 2주간 경험한 자살사고를 0 3점으로 평가하는 4문 항으로 구성되어 있으며, 총점은 0 12점이다. 총점이 높을 수록 자살사고 수준이 높다는 것을 의미하며, 한국판의 경우 4점 이상은 자살 위험군으로 분류한다. Suh 등의 연구에서 내적 일치도 계수(Cronbach's $\alpha$ )는 0.93이며, 본 연구에서의 내적 일치도 계수(Cronbach's $\alpha$ )는 0.92이다. ${ }^{24}$

\section{자료 분석}

본 연구의 자료 분석은 SPSS 21.0 version (IBM Corp., Armonk, NY, USA)과 Mplus 7.11(Muthen \& Muthen, Los Angeles, CA, USA)을 사용하였으며, 다음과 같이 분석을 실 시하였다.

첫째, 연구 대상자의 인구 통계학적 특성과 측정 변수들의 평균 및 표준편차를 알아보고자 기술 통계와 빈도 분석을 실시하였다.

둘째, 한국판 BPS의 내적 일관성 신뢰도를 검증하고자 내 적 일치도 계수(Cronbach's $\alpha$ )를 구할 수 있는 신뢰도 분석 을 실시하였다.

셋째, 한국판 BPS의 수렴 타당도를 검증하기 위해 BPS와 GPS 간의 Pearson 상관분석을 실시하였으며, 그 외에도 각 측정 변수들과 BPS 간의 Pearson 상관 분석을 실시하였다.

넷째, 한국판 BPS의 내적 구조를 평가하기 위해 탐색적 
요인 분석을 실시하였다. 본 연구는 BPS에 대한 이론적 가 설이 충분하지 않고 기존의 타당화 논문이 존재하지 않으므 로 탐색적 요인 분석이 적합하다고 판단하여 실시하였다.

\section{결 과}

\section{인구 통계학적 특성}

본 연구에서 총 227 명의 자료를 수집하였으며, 연구 대상 자의 인구 통계학적 특성은 다음과 같다. 연구 대상자의 평 균 연령은 $22( \pm 2.39)$ 세였다. 연구 대상자의 성별 분포는 여 성이 $81.1 \%(\mathrm{n}=184)$ 였으며, 교육 수준은 대학교 재학 중이 가장 많았고, 대학교 졸업 이상이 그 뒤를 이었다.

본 연구에서는 수집한 각 척도의 평균 및 표준 편차는 $\mathrm{Ta}-$ ble 1에 제시하였으며, 전체 연구 대상자 227명 중 GPS를 실 시한 173 명의 자료가 타당도 분석에 포함되었다.

\section{$\mathrm{BPS}$ 의 신뢰도 검증}

$\mathrm{BPS}$ 의 신뢰도 검증을 위해 전체 9개 문항의 내적 일치도 계수(Cronbach's $\alpha$ )를 산출하였다. Kroese 등의 연구에서의 Cronbach's $\alpha=0.92$ 이며, 본 연구에서 전체 표본 227 명을 대 상으로 9 개 문항에 대한 내적 일관성 신뢰도 분석을 한 결 과, Cronbach's $\alpha=0.86$ 으로 비교적 양호하게 나타났다. ${ }^{8}$ 이 를 통해 BPS 문항 간에 일관성이 있음을 확인할 수 있었다.

\section{$\mathrm{BPS}$ 의 타당도 검증}

\section{BPS의 수렴 타당도}

본 연구에서는 BPS의 타당도를 검증하기 위해 GPS와의 Pearson 상관분석을 실시하였다. GPS와의 수렴 타당도를 확인한 결과 유의한 상관관계를 보여 $(p<0.001, \mathrm{r}=0.411)$

Table 1. Descriptive statistics of instruments $(n=227, \mathrm{GPS}=173)$

\begin{tabular}{lcrrrr}
\hline $\begin{array}{c}\text { Clinical and } \\
\text { sleep indicators }\end{array}$ & $\mathrm{n}$ & Mean & SD & Min & Max \\
\hline BPS & 227 & 29.68 & 7.34 & 11 & 44 \\
ISI & 227 & 10.07 & 5.08 & 0 & 28 \\
CES-D & 227 & 17.70 & 10.50 & 0 & 55 \\
PSS & 227 & 19.13 & 4.55 & 8 & 32 \\
DSI-SS & 227 & 0.95 & 1.70 & 0 & 8 \\
GPS & 173 & 55.53 & 12.62 & 22 & 89 \\
\hline
\end{tabular}

BPS: Bedtime Procrastination Scale, ISI: Insomnia Severity Index, CES-D: Center for Epidemiologic Studies Depression Scale, PSS: Perceived Stress Scale, DSI-SS: Depressive Symptom InventorySuicidality Subscale, GPS: General Procrastination Scale, SD: standard deviation
$\mathrm{BPS}$ 가 타당한 도구임을 확인할 수 있었다.

\section{$\mathrm{BPS}$ 의 내적 구조}

\section{자료의 적합성}

본 연구는 취침시간 지연행동 척도의 요인 분석을 실시하 기 전에 표본 자료가 요인 분석에 적절한 자료인지를 확인 하기 위해 표집 적절성 지수(Kaiser-Meyer-Olkin, KMO) 와 Bartlett's 구형성 검증을 실시하였다. Bartlett's 구형성 검 증 결과는 유의했으며 $\left(\chi^{2}=898.144, \mathrm{df}=36, p<0.001\right), \mathrm{KMO}$ 결과 값은 0.902로 나타났다. Kaiser의 연구에 따르면 $\mathrm{KMO}$ 값이 0.90 이상이면 요인 분석에 사용하기에 매우 적절한 값 이므로 본 연구의 표본 자료가 요인 분석에 적합하다는 것 을 확인할 수 있었다. ${ }^{25}$

\section{요인 수효 결정 및 모형 선택}

본 연구는 요인의 수를 결정하기 위해 스크리 도표(scree plot)와 고유치(eigenvalue)를 사용하여 대략적인 요인 수효 를 결정하고, 탐색적 요인 분석을 통해 최종 모형을 선택하 였다. 고유치가 1 보다 크면 요인의 수가 적절하다고 판단하 므로, 스크리 도표(scree plot)와 고유치에 따르면 1 요인 또 는 2 요인 모형을 제시하고 있음을 알 수 있다(Fig. 1).

다음으로, 최종 모형을 결정하기 위해 탐색적 요인 분석(Exploratory Factor Analysis)을 통해 모형 합치도를 확인하였

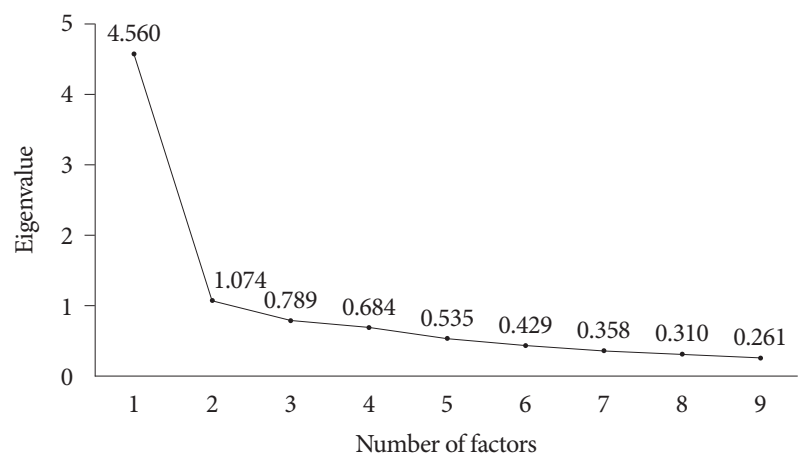

Figure 1. Scree plot and eigenvalue of Bedtime Procrastination Scale.

Table 2. Goodness-fit indices for exploratory factor model of BPS $(\mathrm{n}=227)$

\begin{tabular}{ccccccc}
\hline $\begin{array}{c}\text { Number of } \\
\text { factors }\end{array}$ & $\chi^{2}(\mathrm{df})$ & $p$ & CFI & TLI & RMSEA & SRMR \\
\hline 1-factor & $59.369(27)$ & 0.000 & 0.963 & 0.951 & 0.073 & 0.042 \\
2-factor & $34.031(19)$ & 0.018 & 0.983 & 0.968 & 0.059 & 0.026 \\
\hline
\end{tabular}

BPS: Bedtime Procrastination Scale, CFI: Comparative Fit Index, TLI: Tucker-Lewis Index, RMSEA: Root Mean Square Error of Approximation, SRMR: Standardized Root Mean Square Residual 
An $\mathrm{H}$ et al.

다. 모형 합치도를 판단하는 기준으로 $\chi^{2}$, Comparative Fit Index(CFI), Tucker-Lewis Index(TLI), Root Mean Square Error of Approximation(RMSEA), Standardized Root Mean Square Residual(SRMR) 지수를 참조하였다. 이에 대해 Vandenberg와 Lance가 제시한 기준은 CFI와 TLI는 0.90 이상, RMSEA는 0.08 이하, SRMR은 0.10 이하였으며, Hu와 Bentler 가 $\mathrm{CFI}$ 와 $\mathrm{TLI}$ 는 0.95 이상, RMSEA는 0.06 이하, SRMR은 0.08 이하일 경우 모형이 적합하다고 제시하였다. ${ }^{26,27}$

1 요인 모형과 2 요인 모형의 합치도 지표는 Table 2 와 같 다. 1 요인과 2 요인 모형 모두 CFI와 TLI가 0.95 이상이고, $\mathrm{RMSEA}$ 와 SRMR은 0.08 이하로 나타났다. 전반적으로 2 요인 모형의 합치도가 $\mathrm{Hu}$ 와 Bentler가 제시한 비교적 엄격 한 기준에 부합하지만 1 요인 모형의 합치도 또한 Vandenberg와 Lance가 제시한 기준을 충족하며, ${ }^{26,27}$ Kroese 등의 연구에서 1 요인 모형을 제시한 것을 참조하여 본 연구에서 는 $\mathrm{BPS}$ 의 요인 구조를 1 요인 모형으로 최종 결정하고, 요인 회전을 실시하였다. ${ }^{8}$

\section{1 요인 모형 탐색적 회전 분석}

본 연구는 BPS에 대해 1 요인 모형을 채택하고, 탐색적 회 전 분석을 통한 문항 분석을 실시하였다. 사각 회전을 실시 하여 각 문항의 요인 부하량을 살펴본 결과는 Table 3에 나 타나 있다.

Chung 등의 연구에 따르면 요인 부하량이 0.30 이상일 경우 해석 가능한 크기의 요인 부하량으로 본다. ${ }^{28}$ 이에 따라 BPS의 전체 문항을 유지하였으며, 전체 문항이 요인 1 에 대한 지표 임을 확인할 수 있었다.

\section{$\mathrm{BPS}$ 와 심리적 변인 간의 관련성}

$\mathrm{BPS}$ 와 다른 임상지표 간의 상관을 확인한 결과는 Table 4 에 나타나 있다. BPS는 ISI와 CES-D, PSS, GPS와 정적으 로 유의한 상관관계를 나타냈으며 $(p<0.001), \mathrm{DSI}-\mathrm{SS}$ 와도 상관관계가 유의하였다 $(p<0.05)$.

\section{고 찰}

본 연구는 20 30대 젊은 성인 227명을 대상으로 한국판 취침시간 지연행동 척도(BPS)를 타당화하고, 취침시간 지연 행동의 심리적 특성을 추가적으로 알아보기 위해 본 척도와 불면증 심각도, 우울, 지각된 스트레스, 자살사고 사이의 관 련성을 확인하였다.

본 연구의 주요 결과는 다음과 같다. 첫째, 한국판 $\mathrm{BPS}$ 의 내적 일관성 신뢰도를 확인하기 위해 내적 일관성 신뢰도
Table 3. Factor loadings estimates after geomin rotation

\begin{tabular}{lc}
\hline \multicolumn{1}{c}{ Items } & Factor 1 \\
\hline $\begin{array}{l}\text { Q1. I go to bed later than I had intended } \\
\text { Q2. I go to bed early if I have to get up early in the }\end{array}$ & $0.780^{*}$ \\
$\quad$ morning & $0.338^{*}$ \\
Q3. If it is time to turn off the lights at night I do it & $0.307^{*}$ \\
$\quad$ immediately & \\
Q4. Often I am still doing other things when it is time & $0.748^{*}$ \\
$\quad$ to go to bed & \\
$\begin{array}{l}\text { Q5. I easily get distracted by things when I actually } \\
\quad \text { would like to go to bed }\end{array}$ & $0.790^{*}$ \\
Q6. I do not go to bed on time & $0.820^{*}$ \\
Q7. I have a regular bedtime which I keep to & $0.525^{*}$ \\
Q8. I want to go to bed on time but I just do not & $0.834^{*}$ \\
Q9. I can easily stop with my activities when it is time & $0.682^{*}$ \\
$\quad$ to go to bed & \\
\hline
\end{tabular}

Table 4. Correlation between Instruments ( $n=227$, GPS $=173$ )

\begin{tabular}{lllllll}
\hline $\begin{array}{c}\text { Clinical and } \\
\text { sleep indicators }\end{array}$ & BPS & ISI & CES-D & PSS & DSI-SS & GPS \\
\hline BPS & & & & & \\
ISI & $0.463^{\ddagger}$ & & & & \\
CES-D & $0.303^{\ddagger}$ & $0.488^{\ddagger}$ & & & \\
PSS & $0.252^{\ddagger}$ & $0.381^{\ddagger}$ & $0.679^{\ddagger}$ & & \\
DSI-SS & $0.134^{*}$ & 0.126 & $0.498^{\ddagger}$ & $0.325^{\ddagger}$ & \\
GPS & $0.411^{\ddagger}$ & $0.232^{\dagger}$ & $0.339^{\ddagger}$ & $0.341^{\ddagger}$ & $0.168^{*}$ \\
\hline
\end{tabular}

${ }^{*} p<0.05,{ }^{\dagger} p<0.01,{ }^{\ddagger} p<0.001$. BPS: Bedtime Procrastination Scale, ISI: Insomnia Severity Index, CES-D: Center for Epidemiologic Studies Depression Scale, PSS: Perceived Stress Scale, DSI-SS: Depressive Symptom Inventory-Suicidality Subscale, GPS: General Procrastination Scale

계수를 살펴보았다. 한국판 BPS의 Cronbach's $\alpha$ 는 0.86으 로, 이는 Kroese 등에서의 0.92 에는 미치지 못하지만 양호한 수준인 것으로 나타났다. ${ }^{8}$ 둘째, 한국판 BPS의 수렴 타당도 를 검증하기 위해 GPS와의 관계를 살펴보았으며, 한국판 $\mathrm{BPS}$ 와 GPS의 상관관계가 유의하게 나타났다 $(p<0.001)$. 선 행연구에 따르면 취침시간 지연행동과 일반 지연행동이 서 로 관련 있는 것으로 밝혀졌으며, 이에 따라 한국판 BPS의 수렴 타당도가 지지되었다.,8 셋째, 한국판 BPS의 내적 구조 를 탐색적 요인 분석을 통해 확인한 결과, 최종적으로 1 요 인 구조를 채택하였다. 이후 실시한 탐색적 회전 분석의 결 과, 모든 문항의 요인 부하량이 0.3 을 넘는 것으로 드러나 한 국판 BPS의 모든 문항을 유지하였으며 모든 문항이 요인 1 에 대한 지표임을 확인하였다. 결과적으로 하나의 요인으로 이루어진 것으로 밝혀졌으므로, 즉 $\mathrm{BPS}$ 의 전체 문항은 '취 
침시간 지연행동'이라는 하나의 요인으로 구성되었다고 설 명할 수 있다. 마지막으로, 한국판 BPS와 불면증 심각도, 우 울, 지각된 스트레스, 자살사고와의 관련성을 살펴본 결과, 취침시간 지연행동의 정도가 높을수록 심각한 불면증과 우 울, 지각된 스트레스 및 자살사고의 증상을 보고하는 것으로 드러났다. 이는 취침시간 지연행동의 심리적 특성으로 불면 증과 우울, 지각된 스트레스, 자살사고가 존재할 수 있음을 제기하며, 동시에 취침시간 지연행동의 기제와 취침시간 지 연행동이 미칠 수 있는 부정적인 영향을 암시한다. 이러한 결과를 바탕으로, 취침시간 지연행동에 대한 심도 깊은 연구 와 적절한 개입이 필요함을 시사한다.

종합하면 본 연구를 통해 20 30대 성인을 대상으로 실시 한 한국판 BPS의 타당도와 신뢰도가 검증되었으며, 이는 한 국판 BPS가 취침시간 지연행동을 측정할 수 있는 타당하고 신뢰도가 높은 도구임을 입증한다. 또한 취침시간 지연행동 의 수준이 높은 경우 수면 및 정서적 문제를 보고할 수 있음 을 시사한다.

이를 바탕으로 한 본 연구의 제한점 및 후속 연구를 위한 제언은 다음과 같다. 첫째, 첫 검사 실시 후 재검사를 실시하 지 않아, 검사-재검사 신뢰도의 측정을 통해 시간에 따른 안 정성을 확보하지 못했다는 제한점이 있다. 따라서 후속연구 에서는 검사-재검사 신뢰도의 검증을 통해 시간 경과에 따 른 점수의 일관성을 확보할 필요성이 제기된다. 둘째, 본 연 구에서 모집된 표본의 약 $80 \%$ 가 여성이며, 평균 22세의 초 기 성인기로 구성되었다는 점에서 분석 결과의 전체 인구에 일반화를 하는 데 있어 주의를 요한다. 따라서 이후에 남성 표본과 다양한 연령의 표본을 추가하여 신뢰도 및 타당도를 추가적으로 탐색해 보완할 필요성이 있다. 셋째, 실제 취침 시간 지연행동 시간과의 타당도를 확인하지 않았다는 점에 서 타당도 검증에 한계가 있다. 따라서 후속연구에서는 수면 일지를 통해 실제 취침시간 지연행동의 시간을 측정하여 $\mathrm{BPS}$ 의 수렴 타당도를 추가적으로 확보할 것을 제안한다. 넷 째, 한국판 $\mathrm{BPS}$ 는 취침시간 지연행동의 정도 및 경과 추이 를 살펴보는 데 유용한 도구임이 밝혀졌지만, 상위군과 하위 군을 선별할 수 있는 절단점을 확인하지 않았다. 따라서 후 속연구에서 수면 일지와의 비교를 통해 한국판 BPS의 절단 점을 도출할 것을 제안하며, 이를 통해 $\mathrm{BPS}$ 는 향후 취침시 간 지연행동의 정도뿐만 아니라 취침시간 지연행동군을 구 분할 수 있는 기준점으로 활용될 수 있을 것이다. 여러 제한 점에도 불구하고 본 연구는 BPS가 취침시간 지연행동을 측 정할 수 있는 유일한 자기보고식 도구이며, 취침시간 지연행 동에 대한 여러 연구에 사용되었지만 국내외에서 척도의 신 뢰도 및 타당도가 검증된 바 없는 BPS에 대해 타당화 연구
를 실시하였다는 데 그 의의가 있다. 또한 본 연구의 결과를 통해 한국판 BPS가 취침시간 지연행동에 대한 타당하고 신 뢰도가 높은 도구임이 밝혀져 여러 연구에서 유용하게 사용 될 수 있고, 취침시간 지연행동에 대한 개입 장면에서 활발 히 활용될 수 있을 것으로 기대된다. 더불어 본 연구를 통해 밝혀진 취침시간 지연행동과 불면증 심각도와 우울, 지각된 스트레스, 자살사고와 관련성을 바탕으로 취침시간 지연행 동에 대한 개입의 필요성이 시사되며, 심리적 개입 연구의 바탕이 될 것으로 기대된다.

\section{Conflicts of Interest}

The authors have no potential conflicts of interest to disclose.

\section{Acknowledgments}

This work was supported by the Ministry of Education of the Republic of Korea and the National Research Foundation of Korea(NRF-2018S1A 5A8026807).

\section{ORCID iDs}

Hyeyoung An

Sun ju Chung

Sooyeon Suh

https://orcid.org/0000-0003-2450-3924 https://orcid.org/0000-0002-6613-5480 https://orcid.org/0000-0003-0644-8634

\section{Author Contributions}

Conceptualization: Hyeyoung An, Sooyeon Suh. Data curation: Sun ju Chung. Formal analysis: Hyeyoung An. Funding acquisition: Sooyeon Suh. Investigation: Hyeyoung An, Sooyeon Suh. Methodology: Hyeyoung An, Sooyeon Suh, Sun ju Chung. Resources: Sun ju Chung, Sooyeon Suh. Supervision: Sooyeon Suh. Validation: Sun ju Chung, Hyeyoung An. Writing_original draft: Hyeyoung An. Writing - review \& editing: Sooyeon Suh, Hyeyoung An.

\section{REFERENCES}

1. Pilcher JJ, Huffcutt AI. Effects of sleep deprivation on performance: a meta-analysis. Sleep 1996;19:318-326.

2. Hublin C, Kaprio J, Partinen M, Koskenvuo M. Insufficient sleep--a population-based study in adults. Sleep 2001;24:392-400.

3. Kroese FM, Evers C, Adriaanse MA, de Ridder DTD. Bedtime procrastination: a self-regulation perspective on sleep insufficiency in the general population. J Health Psychol 2016;21:853-862.

4. National Youth Policy Institute. The survey on rights of the children \& youths in 2016. KOSIS 2016 [updated 2017 Jun 8]. URL:http://kosis. $\mathrm{kr} / \mathrm{statHtml} /$ statHtml.do?orgId=402\&tblId=DT_ES2016_002\&conn path=I3. Access date 2019 May 29.

5. Markwald RR, Melanson EL, Smith MR, et al. Impact of insufficient sleep on total daily energy expenditure, food intake, and weight gain. Proc Natl Acad Sci U S A 2013;110:5695-5700.

6. Dahl RE. The consequences of insufficient sleep for adolescents: links between sleep and emotional regulation. Phi Delta Kappan 1999;80: 354-359.

7. Lee J, Kang J, Rhie S, Chae KY. Impact of sleep duration on emotional status in adolescents. J Korean Child Neurol Soc 2013;21:100-110.

8. Kroese FM, De Ridder DT, Evers C, Adriaanse MA. Bedtime procrastination: introducing a new area of procrastination. Front Psychol 2014; 5:611.

9. Lay CH. At last, my research article on procrastination. J Res Pers 1986;20:474-495.

10. Steel P. The nature of procrastination: a meta-analytic and theoretical 
review of quintessential self-regulatory failure. Psychol Bull 2007;133: 65-94.

11. Sirois FM, Nauts S, Molnar DS. Self-compassion and bedtime procrastination: an emotion regulation perspective. Mindfulness 2019;10:434-445.

12. Kühnel J, Syrek CJ, Dreher A. Why don't you go to bed on time? A daily diary study on the relationships between chronotype, self-control resources and the phenomenon of bedtime procrastination. Front Psychol 2018;9:77.

13. Exelmans L, Van den Bulck J. "Glued to the Tube": the interplay between self-control, evening television viewing, and bedtime procrastination. Communic Res 2017 Jan 6 [Epub ahead of print]. https://doi. org/10.1177/0093650216686877.

14. Park MJ, Ryu SY, Park J, Han MA. The effects of smartphone addiction on sleeping time and sleep deprivation among some college students. J Health Info Stat 2015;40:50-61.

15. McCown W, Roberts R. A study of academic and work-related dysfunctioning relevant to the college version of an indirect measure of impulsive behavior. Integra Technical Paper 1994;28:94-98.

16. Lim SM. The relation between early maladaptive schemas and chronic procrastination of college students. Studies on Korean Youth 2006;17: 185-211.

17. Bastien CH, Vallières A, Morin CM. Validation of the Insomnia Severity Index as an outcome measure for insomnia research. Sleep Med 2001;2:297-307.

18. Cho YW, Song ML, Morin CM. Validation of a Korean version of the insomnia severity index. J Clin Neurol 2014;10:210-215.

19. Radloff LS. The CES-D scale: a self-report depression scale for research in the general population. Appl Psychol Meas 1977;1:385-401.

20. Chon KK, Choi SC, Yang BC. Integrated adaptation of CES-D in Korea. Kor J Psychol: Health 2001;6:59-76.

21. Cohen S, Kamarck T, Mermelstein R. A global measure of perceived stress. J Health Soc Behav 1983;24:385-396.

22. Park JO, Seo YS. Validation of the Perceived Stress Scale (PSS) on samples of Korean university students. Kor J Psychol: Gen 2010;29:611-629.

23. Metalsky GI, Joiner Jr TE. The hopelessness depression symptom questionnaire. Cognit Ther Res 1997;21:359-384.

24. Suh S, Ryu H, Chu C, Hom M, Rogers ML, Joiner T. Validation of the Korean Depressive Symptom Inventory-suicidality subscale. Psychiatry Investig 2017;14:577-584.

25. Kaiser HF. An index of factorial simplicity. Psychometrika 1974;39:31-36.

26. Vandenberg RJ, Lance CE. A review and synthesis of the measurement invariance literature: suggestions, practices, and recommendations for organizational research. Organ Res Methods 2000;3:4-70.

27. Hu LT, Bentler PM. Cutoff criteria for fit indexes in covariance structure analysis: conventional criteria versus new alternatives. Struct Equ Modeling 1999;6:1-55.

28. Chung F, Yegneswaran B, Liao P, et al. STOP questionnaire: a tool to screen patients for obstructive sleep apnea. Anesthesiology 2008;108: 812-821. 